\title{
FUZZY LOGIC AND PSO BASED HYBRID TECHNIQUE FORMULATION FOR OPTIMAL PLACEMENT AND SIZING OF INTERLINE POWER FLOW CONTROLLER
}

\author{
B.V.Rami Reddy*, Dr. P.Sujatha**, Dr.Y.V.Siva Reddy*** \\ *Department of Electrical and Electronics Engineering, Ravindra College of Engineering for Women, \\ Kurnool - 518 002, Andhra Pradesh, India. tel. +91 9441150088, e-mail: ramireddybv@ gmail.com \\ ** Department of Electrical and Electronics Engineering, Jawaharlal Nehru Technical University Ananthapur, \\ Ananthapuramu 518 002, Andhra Pradesh, India. \\ ***Department of Electrical and Electronics Engineering, G.Pulla Reddy Engineering College, \\ Kurnool - 518 002, Andhra Pradesh, India.
}

\begin{abstract}
Maximum utilization of the available transmission lines is advisable than introducing a new transmission line to the existing power system because of various reasons such as regulatory, environmental, and public policies, as well as escalating costs. This can be achieved by using FACTS controllers which are one of the power electronics based static equipment to control one or more AC transmission system parameters for enhancing controllability and increase power transfer capability. Placing and Sizing of the FACTS controllers in transmission line is a challenging task. To perform this task, we propose a new hybrid technique based on fuzzy logic (FL) and Particle swarm optimization (PSO). Here, we have considered Interline Power Flow Controller (IPFC) as we are discussing multiline transmission systems. The purpose of fuzzy system is to determine the capacity of IPFC in terms of voltage deviation. The optimal location of IPFC is done by PSO. The proposed technique maintains the voltage stability and minimizes the transmission loss of the power system. For analyzing the nonlinear power flow of the transmission system, Newton-Raphson method is utilized. The proposed multi objective approach is implemented in MATLAB and the performance of the proposed fuzzy-PSO is compared with fuzzy-GA.
\end{abstract}

Keywords: power system, voltage stability, IPFC, optimal location, transmission loss, Fuzzy Logic and PSO.

\section{INTRODUCTION}

Recently, several network blackouts have been related to voltage collapses. This phenomenon tends to occur from lack of reactive power support in heavily stressed conditions, usually triggered by system faults [1]. The reactive power support can be provided by special devices called as Flexible Alternating Current Transmission System (FACTS) devices. Moreover better utilization of the existing power system resources can be increased by installing FACTS controllers with economic cost [2]. The FACTS devices are the latest power electronics devices by which losses can be reduced and transfer capability can be enhanced [3]. The performance of FACTS devices mainly depends upon suitable location in the power network and its parameters [4]. Because of their adaptability and fast control characteristics, FACTS devices are capable of handling the active and reactive power control and can simultaneously maintain constant voltage-magnitude with in the acceptable range [5]. FACTS devices help in the improvement of system dynamic behaviour and enhancement of system reliability [6].

Different kinds of FACTS devices are available and their different locations have varying advantages [7][8]. The FACTS devices such as Static VAR Compensator (SVC), Thyristor Controlled Series Capacitor (TCSC), Static Synchronous Series Compensator (SSSC), Static Synchronous Compensator (STATCOM), Unified Power Flow Controller (UPFC) and Interlink Power Flow Controller (IPFC) are available in the literature for power flow control in transmission systems [9]. The IPFC is a new and advanced FACTS device aimed at simultaneously controlling the power flow in multiline systems in a substation [10]. IPFC employs Voltage Source Inverter
(VSI) as basic building block [11][12]. Generally, it composes of two VSIs and these are able to transfer real power to any other line and thereby facilitate real power transfer among the lines, together with independently controllable reactive series compensation of each individual line [13].

IPFC is presented as a power injection model and is implemented to study the effect of IPFC parameters on bus voltages, active and reactive power flows in the lines [14] [15]. The applications of IPFC to improve damping of the system are reported by few researches and they have applied IPFC to improve transient stability of power system [16]. It can also be utilized to compensate against reactive voltage drops and the corresponding reactive line power and to increase the effectiveness of the compensating system against dynamic disturbances [17]. The minimization of generation cost, transmission losses and maximization of the loadability of the transmission system can be achieved by optimally placing IPFC. Different operating conditions of the power system must be considered while determining the optimal choice and location of the power flow controller.

In this paper, the Fuzzy Logic (FL) and Particle Swarm Optimization (PSO) based hybrid technique proposed for optimizing the IPFC capacity and location. The capacity of IPFC is determined by FL controller and the optimal location of IPFC is determined by PSO. FL controllers are based on empirical control rules [18]. The FL Controller provides an algorithm which can convert the linguistic control strategy, based on expert knowledge, to automatic control strategies and replaces a skilled human operator [19]. One of the recently developed algorithms for optimization problems is PSO algorithm which inspired by 
the social behaviour of swarms (birds and fishes) [20]. Recent research works on FACTS controllers are illustrated in section 2. In section 3, the hybrid technique based on FL and PSO is described clearly. The results and discussion of the proposed work is given in Section 4. At last in Section 5 , conclusions are provided.

\section{MULTI-OBJECTIVE FORMULATION FOR PLACEMENT \& SIZING OF IPFC}

FACTS controllers are capable of controlling the network condition in a very fast manner and this feature of FACTS can be exploited to improve the voltage stability, steady state and transient stabilities of a complex power system. This allows increased utilization of existing network closer to its thermal loading capacity and thus avoiding the need to construct new transmission lines. Afore said benefits are achieved by optimally placing the FACTS devices in the transmission lines. The position of the FACTS device is decided such that it maximizes the distance between the current operating point and the faulted point of the power system. Voltage instability problem appears whenever any bus voltage deviates from its permissible limits. The permissible range of bus voltage is 0.95 p.u. to 1.05 p.u.. Both high voltage and low voltage results in undesirable service quality. The size/capacity of the FACTS device is also important parameter to consider because excess size will lead to extra cost as well as more total power losses. So, optimal placing and sizing of a FACTS device is multi-objective optimization problem which is based on voltage deviation of the violated bus and capacity of the FACTS device to be connected at that bus. Hence, here the first objective is to minimize the bus voltage deviation.

\subsection{Minimum voltage deviation}

Voltage deviation at a bus is the difference between the actual voltage and the possible limits at the bus. Voltage deviation is a constraint which helps in desirable improvement of the voltage profile of a transmission line. Excessively low voltages or high voltages at a bus can lead to an unacceptable service quality and can create voltage instability problems in the whole system. The mitigation of the voltage deviations can be effectively achieved by placing a FACTS device in the transmission line. The minimization of voltage deviation is formulated in equation (1)

$$
\min f_{v}=\sum_{i=1}^{n}\left|V_{\text {iref }}-V_{i}\right|
$$

Where, $V_{i}$ and $V_{\text {iref }}$ are the voltage magnitude and nominal voltage of $i^{\text {th }}$ bus and $n$ is the number of buses for which voltage limit is violated.

\subsubsection{Minimum capacity of the FACTS devices}

The capacity of the FACTS controller plays an important role in installation of it. This is because of their expensiveness than the conventional ones. Excess size of FATCS device will lead to the increment of total power losses. So, better performance of the transmission system can be drawn by keeping the exact size as per required. Therefore, the second objective function is to minimize the capacity of shunt FACTS device. It can be expressed as,

$\min f_{c}=\sum_{j=1}^{k} C_{j}$

Where, $C_{j}$ is the capacity of the $j^{\text {th }}$ shunt FACTS device in p.u. and $k$ is the total number of shunt FACTS devices.

For any optimization problem like IPFC placement in power system, certain constraints are required to be satisfied. These constraints are as described below.

\subsubsection{Load constraint}

Equality constraints of the problem are the active and reactive power balance equations. These are also called as load constraints and expressed in a compact form as,

$P(x, y)=0$

Where $x$ is a vector of dependant variables consisting of slack bus power $P_{G 1}$, load bus voltages $V_{L}$ and generator reactive power outputs $Q_{G} . y$ is a vector of independent variables consisting of generator voltages $V_{G}$, generator real power outputs $P_{G}$, except the slack bus power $P_{G 1}$ and shunt VAR compensations $Q_{c}$.

\subsubsection{Operational Constraint}

Inequality constraint of the problem are shown in below equation

$q(x, y) \leq 0$

Where, $q$ is the system operating constraint that includes generator voltages, their real and reactive power outputs and shunt VAR compensation. These are restricted by their limits as follows:

$$
\begin{aligned}
& V_{G_{i}}^{\min } \leq V_{G_{i}} \leq V_{G_{i}}^{\max }, \quad i=1, \ldots \ldots N G \\
& P_{G_{i}}^{\min } \leq P_{G_{i}} \leq P_{G_{i}}^{\max }, \quad i=1, \ldots \ldots N G \\
& Q_{G_{i}}^{\min } \leq Q_{G_{i}} \leq Q_{G_{i}}^{\max }, \quad i=1, \ldots \ldots N G \\
& Q_{C_{i}}^{\min } \leq Q_{C} \leq Q_{C_{i}}^{\max }, \quad i=1, \ldots \ldots N C
\end{aligned}
$$

Where, $N G$ and $N C$ are the total number of generators and shunt compensators, respectively.

By Considering the objectives and constraints the problem of optimal placement and sizing of shunt compensation can be mathematically formulated as a nonlinear constrained multi objective optimization problem as follows:

$$
\begin{gathered}
\min \boldsymbol{f}_{\boldsymbol{v}}=\sum_{\boldsymbol{i}=\mathbf{1}}^{\boldsymbol{n}}\left|\boldsymbol{V}_{\boldsymbol{i r e f}}-\boldsymbol{V}_{\boldsymbol{i}}\right| \text { and } \min \boldsymbol{f}_{\boldsymbol{c}}=\sum_{\boldsymbol{j}=\mathbf{1}}^{\boldsymbol{k}} \boldsymbol{C}_{\boldsymbol{j}} \\
\text { Subjected to: } P(x, y)=0 \text { and } \\
q(x, y) \leq 0
\end{gathered}
$$


The multi-objective optimization problem is converted into a single objective optimization problem using fuzzy framework.

Based on the objective constraints, the permissible limits of values are used to find the capacity of the IPFC using FL controller. Then, the optimal location of IPFC is achieved by using PSO. After placing the IPFC in the transmission system, active and reactive power injected by it are analyzed using load flow analysis by NewtonRaphson method. IPFC injected power equations are given as follows:

$P_{s, i}=\sum_{n=j, k} V_{i} V_{s_{i n}} b_{i n} \sin \left(\theta_{i}-\theta_{s_{i n}}\right)$

$Q_{s, i}=-\sum_{n=j, k} V_{i} V_{s_{i n}} b_{i n} \cos \left(\theta_{i}-\theta_{s_{i n}}\right)$

$P_{s, n}=-V_{n} V_{s_{i n}} b_{i n} \sin \left(\theta_{n}-\theta_{s_{i n}}\right)$

$Q_{s, n}=V_{n} V_{s_{i n}} b_{i n} \cos \left(\theta_{n}-\theta_{s_{i n}}\right)$

Where:

$\mathrm{n}, \mathrm{i}, \mathrm{j}, \mathrm{k}=$ bus numbers

$\mathrm{V}_{\mathrm{n}}, \mathrm{V}_{\mathrm{i}}, \mathrm{V}_{\mathrm{j}}, \mathrm{V}_{\mathrm{k}}$, = voltages at $\mathrm{n}, \mathrm{i}, \mathrm{j}$ and $\mathrm{k}^{\text {th }}$ busses

$\theta=$ bus voltage angle, $V$ is the bus voltage magnitude, $\theta_{\sin }$ is the angle of the injected voltage, $V_{\text {sin }}$ is the magnitude of the injected voltage, $b_{\text {in }}$ is the imaginary part element in the admittance matrix, $P_{S}$ is the injected active power and $Q_{S}$ is the injected reactive power. The detailed description of FL controller and PSO is given in the following section.

\subsection{Fuzzy based Minimum Active Power Selection}

FL controllers are rule based systems. The aim of fuzzy control systems is to replace a skilled human operator with a fuzzy (if-then) rules-based system and it doesn't need any mathematical expressions to represent system. Three building blocks of FL controller are fuzzification, inference system based on fuzzy rules and defuzzification.

Here, FL controller is used to compute the capacity of IPFC. The inputs are voltage deviation ranges i.e., minimum voltage deviation range and maximum voltage deviation range and are denoted as $V_{\min }$ and $V_{\max }$ respectively. The output of the FL controller is the capacity of IPFC and is denoted as $C_{I P F C}$.

The block diagram of the FLC is shown in Fig. 1.

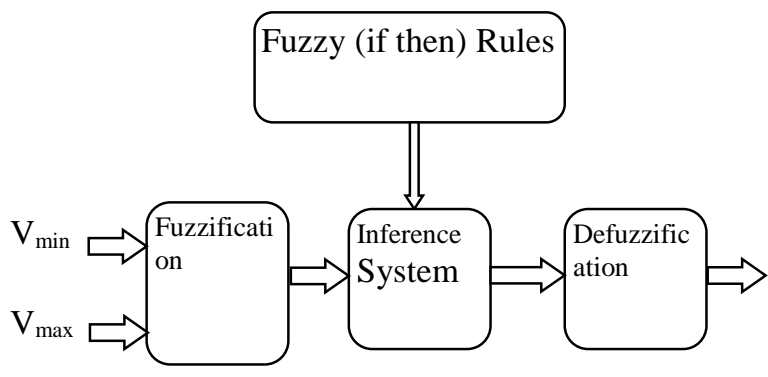

Fig. 1 Structure of Proposed Fuzzy System

The steps of fuzzy is described as following them.

\subsubsection{Fuzzification}

In Fuzzification, inputs and outputs are converted into fuzzy sets from crisp sets. Voltage minimum and maximum deviation ranges are given as inputs and output is capacity of the shunt IPFC. Here, these crisp sets are converted into fuzzy sets. The fuzzy membership functions used are triangular. These fuzzy triangular membership functions of inputs and output are shown in Fig. $2 \& 3$.

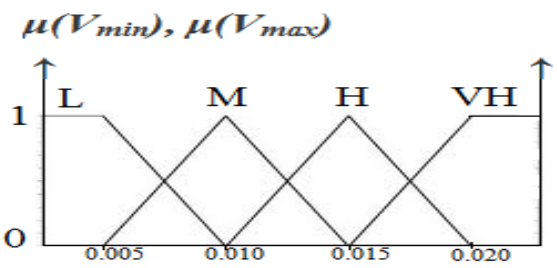

Fig. 2 Triangular membership functions of Voltage deviations

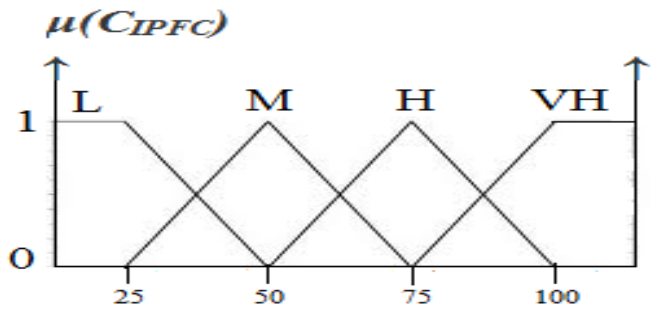

Fig. 3 Triangular membership functions of capacity

Based on the values of voltage deviation and capacity of IPFC, the 'If' 'then' fuzzy rules are generated.

\subsubsection{Inference system}

The next step of Fuzzification is inference system where a decision is taken. It depends on decision making rules and these are called as IF-THEN rules. Here, 'if' is condition statement and 'then' is conclusion statement. So, this system works on the principle that if antecedents condition is true then consequent condition runs. Based on membership functions and experts knowledge, $4 * 4$ decision making rules are prepared. The listed rules are tabulated in Table I. From the listed rules, the voltage deviation and the corresponding IPFC capacity is determined.

Table 1 List of IF-THEN Rules

\begin{tabular}{|c|c|c|c|c|}
\hline $\mathrm{V}_{\min }$ & $\begin{array}{c}\text { Les } \\
\mathrm{s}(\mathrm{L})\end{array}$ & $\begin{array}{c}\text { Mediu } \\
\mathrm{m}(\mathrm{M})\end{array}$ & $\begin{array}{c}\text { Hig } \\
\mathrm{h} \\
(\mathrm{H})\end{array}$ & $\begin{array}{c}\text { Ver } \\
\mathrm{yHigh} \\
(\mathrm{VH})\end{array}$ \\
\hline $\begin{array}{c}\text { Less } \\
(\mathrm{L})\end{array}$ & $\mathrm{L}$ & $\mathrm{M}$ & $\mathrm{M}$ & $\mathrm{M}$ \\
\hline $\begin{array}{c}\text { Mediu } \\
\text { (M) }\end{array}$ & $\mathrm{L}$ & $\mathrm{M}$ & $\mathrm{L}$ & $\mathrm{H}$ \\
\hline $\begin{array}{c}\text { High } \\
(\mathrm{H})\end{array}$ & $\mathrm{M}$ & $\mathrm{M}$ & $\mathrm{H}$ & $\mathrm{H}$ \\
\hline $\begin{array}{c}\text { Very } \\
\text { High (VH) }\end{array}$ & $\mathrm{H}$ & $\mathrm{H}$ & $\mathrm{H}$ & $\mathrm{VH}$ \\
\hline
\end{tabular}




\subsubsection{Defuzzification}

By using IF-THEN rules, capacity of shunt IPFC is obtained. But, it will be in fuzzy set. To convert it into crisp set we use defuzzification. Centroid is the defuzzification method used here. After defuzzification, capacity of the shunt IPFC to be placed in transmission system is obtained in MW.

After IPFC capacity selection, the next process is optimally locate the IPFC in transmission system. It is determined by particle swarm optimization algorithm. That will explain in the following section.

\subsection{Optimal Placement of IPFC using PSO}

Particle Swarm Optimization (PSO) is a technique used to explore the search space of a given problem to find the settings or parameters required to maximize a particular objective [21]. It is inspired by bird flocking and fish schooling intelligence and first described by James Kennedy and Russell C Eberhart [22]. The PSO algorithm is initialized with a population of random candidate solutions, conceptualized as particles. Each particle is assigned a randomized velocity and is iteratively moved through the problem space. It is attracted towards the location of the best fitness achieved so far by the particle itself and by the location of the best fitness achieved so far across the whole population.

Here, PSO is used to find the optimal location of IPFC controller to be placed for improving voltage profile and reducing total power losses by injecting real and reactive powers in the most voltage violated bus. Normally, PSO consists of four stages namely, generating initial particle, evaluation function, updating initial particle, and termination. The initial process of PSO is generating initial particles.

\subsubsection{Generation of Initial Particle}

The initial process in PSO is generation of initial particles. For optimizing the location of IPFC, we have to find the most voltage violated bus and the corresponding size of the IPFC controller. i.e., optimal location depends on the two parameters. They are voltage deviation of the violated bus and its capacity of IPFC. Let us initiate ' $n$ ' number of particles whose dimension is 2 i.e., we are considering the voltage violated buses and their corresponding IPFC capacities required.

Initialization of the particles is described as follows:

$S=\left\{X_{i, t}^{j}\right\} ; 1 \leq i \leq n, j=1,2$.

Where, $S$ is the population of the particles also known as swarm $X_{i, t}^{j}$ is the $i^{t h}$ particle of the swarm at $t^{t h}$ iteration and it is a two dimensional particle $\left(V_{d e v}, C_{I P F C}\right)$. Along with initialization of particles, we have to randomly select its current velocity $\left(V_{i, t}\right)$, best fitness value of its experience $\left(P_{i, \text { best }}\right)$, global best fitness value of any particle in the $\operatorname{swarm}\left(P_{g, b e s t}\right)$. After generating the initial particle, the next step is to evaluate the initial particle using the evaluation function.

\subsubsection{Evaluation Function}

Evaluation function is used in PSO to identify the best particle from the set of initialized particle. The evaluation function used in our method is shown below which is to be maximized.

$\operatorname{Max}\{F(i)\}=V_{d e v}(i) * C_{I P F C}(i)$

Where, $F(i), V_{d e v}(i)$ and $C_{I P F C}(i)$ are the fitness value, voltage deviation and IPFC capacity of the $i^{\text {th }}$ particle (violated bus). As the fitness function proportional to voltage deviation, the maximum fitness function valued particle is the most voltage violated bus.

\subsubsection{Updating Initial Particle}

Updating different particles in the system is an important process in PSO. In this stage, the initial particles generated and are updated and then the evaluation function is applied. The particles are updated using the equation given below,

$$
\begin{aligned}
& V_{i, t+1}=V_{i, t}+C_{1} * \alpha *\left(P_{i, b e s t}-X_{i, t}^{j}\right)+C_{2} * \beta *\left(P_{g, b e s t}-\right. \\
& \left.X_{i, t}^{j}\right) \\
& X_{i, t+1}^{j}=X_{i, t}^{j}+V_{i, t+1}
\end{aligned}
$$

Where, $V_{i, t+1}$ and $X_{i, t+1}^{j}$ are the $i^{\text {th }}$ particle updated velocity and position in the search space, $\alpha$ and $\beta$ are the random number between $(0,1)$, and $C_{1}, C_{2}$ are the learning factors. The next step after updating the initial particle is termination.

\subsubsection{Termination}

In the termination process, the optimal location of the IPFC controller to be placed is selected based on the maximum fitness valued particle in the swarm. By injecting the IPFC controller at that location, we analyze the system for better voltage profile, total power loss reduction and optimal allocation of real and reactive power for maximum power transfer capability. Flow chart for the implemented for PSO is shown in fig. 4. 


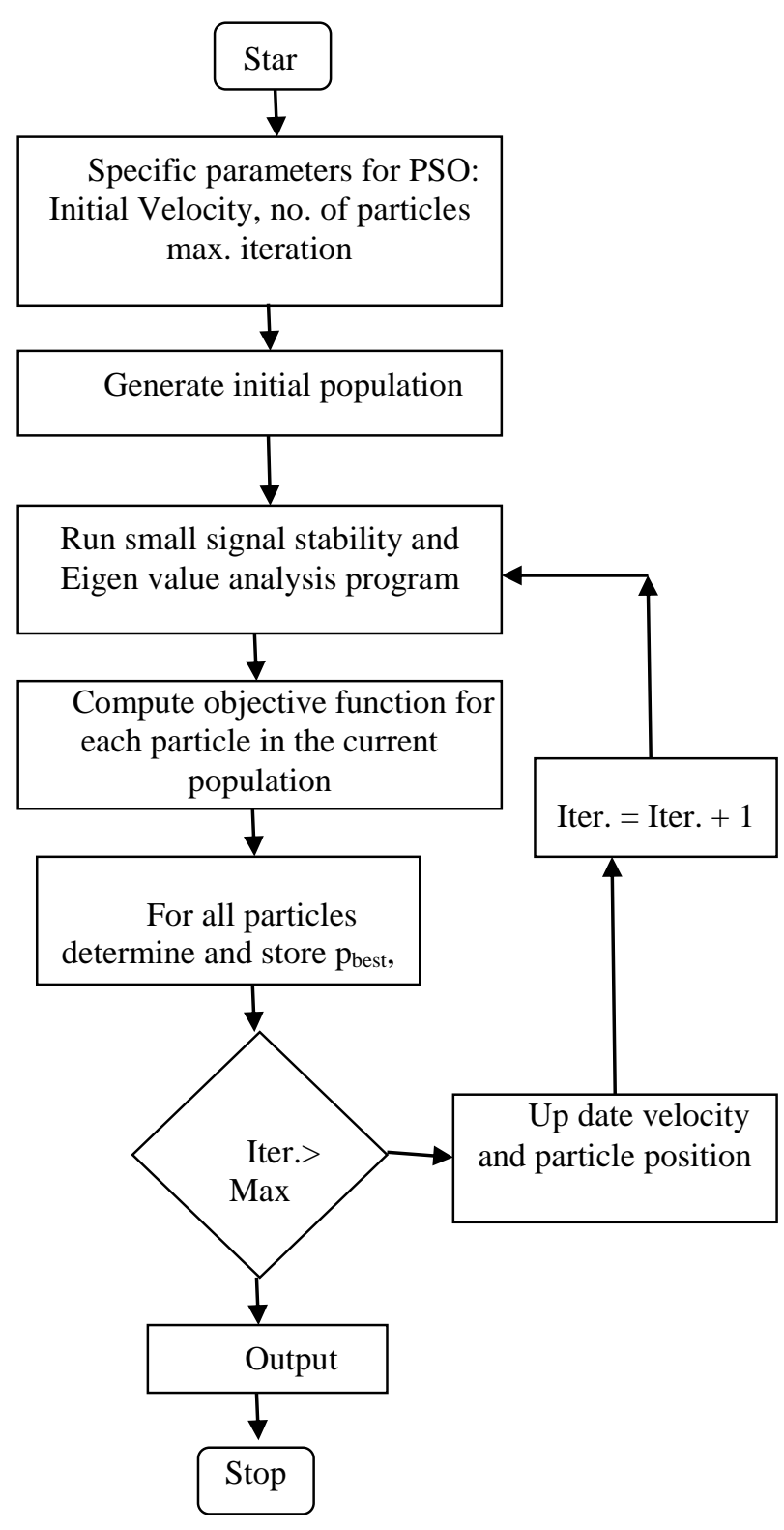

Fig. 4 Flow chart for the implemented for PSO

By using the proposed hybrid method, the optimal location for fixing IPFC is identified using PSO and the corresponding capacity of the IPFC is computed by fuzzy logic. By fixing the IPFC in the optimal location and corresponding capacity using the fuzzy logic, the system voltage profile is improved, total power loss is reduced and the maximum power transfer capability is also increased.

\subsection{Optimal Placement of IPFC using GA}

Genetic algorithm (GA) is an optimization algorithm which is based on the genetic concept. At first different combinations of the chromosomes or the voltages are made and the active power flow in the system is calculated for different combination of chromosomes and the combination that gives the highest active power is determined. The similar process is repeated for getting different outputs by increasing the number of chromosomes. After analyzing the values of power calculated for each combination of chromosomes the genetic algorithm decides the line to which IPFC must be connected so as to increase the active power for balancing the power flow in the transmission lines. The GA-based proposed methodology is consisting of five major stages,

- Initialization.

- Applying fitness function.

- Crossover.

- Mutation.

- Termination.

\subsubsection{Initialization}

Initialization process is nothing but the process of selecting the individual chromosome sets on the basis of the voltage deviation and the capacity of the IPFC. The selection is done in a random manner. It operates with a set of chromosomes called the binary strings. These set of chromosomes or strings is known as a population, and is put through the process of evolution to produce new individual strings. The size of the population depends on the nature and type of fault or disorder, but typically contains several hundreds and thousands of possible outputs. The initial population size is generated on the basis of population size.

$$
\begin{aligned}
X_{i}= & {\left[\begin{array}{lll}
x_{0}^{(i)} & x_{1}^{(i)} \ldots \ldots \ldots x_{P_{L-1}}^{(i)}
\end{array}\right] } \\
& 0 \leq i \leq P_{p}-1,0 \leq j \leq P_{L}-1
\end{aligned}
$$

Where:

$$
\begin{aligned}
& x_{j}^{(i)} \text { is the } \mathrm{j}^{\text {th }} \text { gene of the chromosome. } \\
& \mathrm{P}_{\mathrm{p}} \text { is the population pool. } \\
& \mathrm{P}_{\mathrm{L}} \text { is the length of the chromosome. }
\end{aligned}
$$

Here, the target parameter is to obtain a better voltage profile by finding out the optimal location of the IPFC device to be placed on the transmission lines. Initialization is the first step for achieving this purpose. After the initialization process the fitness function is to be calculated.

\subsubsection{Applying Fitness Function}

The fitness function consists of the two important constraints the voltage deviation and the injection of active and reactive power. At First the feasibility of each generated chromosome is calculated and the fitness of the chromosome is determined by applying the fitness function. After the completion of initialization and generation of chromosomes the amount of power to be injected on each line to which the IPFC is connected is evaluated. Hence, fitness function calculation is an important criteria in finding out the. The amount of active power injection is calculated using the formulas given below,

$F=V_{\text {devi }} * C_{I P F C}$

$F=\sum_{n=1}^{N} V_{\text {devi }}(n) * C_{I P F C}(n)$

Where, $F$ is the fitness function,

$V_{\text {devi }}$ is the voltage deviation,

$C_{I P F C}$ is the capacity of IPFC. 


\subsubsection{Crossover}

In biological language, crossover means a genetically process which includes the mating of two parent chromosomes so as to produce an offspring. Here, the crossover is performed on different combinations of chromosomes at a crossover rate of $\mathrm{C}_{\mathrm{r}}$ to obtain a child $\mathrm{X}_{\text {child }}$ for every parent chromosome. This process is carried out basing on the set of genes present in each of the chromosomes.

\subsubsection{Mutation}

Mutation is a process through we can obtain a new generation from the best initial chromosomes. The chromosomes are mutated by random selection the genes at a mutation rate of $M_{r}$. After the generation of new individuals the best among them is selected. Mathematically, the mutation rate is defined as the ratio of mutation point to that of the chromosome length, it can be shown below,

$$
M_{r}=M_{p} / C_{l}
$$

Where, $M_{r}$ is the mutation rate,

$M_{p}$ is mutation point, and

$C_{l}$ is the chromosome length.

\subsubsection{Termination}

The above steps are repeated until and unless a maximum possible number of iteration is reached. After that a final best chromosome is determined from the set of chromosomes based on its fitness value. This selected chromosome indicates the combination of buses to which the IPFC device be connected. Finally, the optimal fitness values all buses are obtained in terms of voltage deviation and capacity of IPFC. The obtained optimal fitness values are expressed as following them.

$$
\left[\begin{array}{c}
F_{1}^{\max } \\
F_{2}^{\max } \\
\vdots \\
F_{n}^{\max }
\end{array}\right]=\left[\begin{array}{c}
V_{\operatorname{devi}}(1), C_{I P F C}(1) \\
V_{\operatorname{devi}}(2), C_{I P F C}(2) \\
\vdots \\
\vdots \\
V_{\operatorname{devi}}(n), C_{I P F C}(n)
\end{array}\right]
$$

The above equation is the maximum fitness function of voltage deviation and capacity of IPFC. From the maximum fitness function, the optimal location of IPFC is determined in which bus has maximum fitness value that, bus is the optimal bus for connecting IPFC. According to that, the IPFC is connected and the capacity of IPFC is determined from the fuzzy controller. Based on the capacity of IPFC, the active power is injected to the identified bus and the voltage stability, loss and active power improvements of the system is analyzed by load flow analysis.

\section{RESULTS}

The proposed hybrid technique based on FL Controller and PSO was implemented in MATLAB working platform.
Then, the performance of proposed work was tested with IEEE 30 bus transmission system. Initially, the voltage deviation is analyzed from the 30 bus system data set. The voltage deviation was computed by the voltage varied from its nominal voltage i.e. slack bus voltage (1p.u.). The voltage deviation was divided into two ranges based on its maximum and minimum values. According to this deviation range, the capacity of IPFC was determined by the FL controller. Here, the Mamdani type FL controller is used to select the capacity of IPFC and the Centroid method was used for defuzzification. The structure of IEEE 30 bus system is shown in Fig. 5.

In IEEE 30 bus system, the bus 1 is selected as the slack bus, bus number 2, 6, 13, 22 and 27 are generator buses and the other buses are the load buses. From the load buses, the optimal location of IPFC is determined by PSO. Location of the IPFC is based on maximum fitness valued particle in PSO. Because maximum fitness valued bus is the most violated bus in the system. So, it is the optimal bus for connecting IPFC. The optimal bus could be varied due the random initialization of particles in PSO. The optimized bus and the corresponding voltage deviation, capacity of IPFC and the fitness function are tabulated as in Table II.

Table 2 Voltage Deviation, Capacity of IPFC and Fitness

\begin{tabular}{|c|c|c|c|}
\hline $\begin{array}{l}\text { Load } \\
\text { Buses }\end{array}$ & $\begin{array}{l}\text { Voltage } \\
\text { Deviation }\end{array}$ & $\begin{array}{l}\text { Capacity } \\
\text { of IPFC } \\
(\mathrm{MW})\end{array}$ & $\begin{array}{l}\text { Fitness } \\
\text { Function }\end{array}$ \\
\hline 3 & 0.0202 & 18 & 0.3636 \\
\hline 4 & 0.0073 & 51 & 0.3751 \\
\hline 5 & 0.0005 & 61 & 0.0317 \\
\hline 7 & -0.0171 & 55 & -0.9409 \\
\hline 8 & 0.0072 & 79 & 0.5724 \\
\hline 9 & 0.0455 & 16 & 0.728 \\
\hline 10 & 0.0318 & 84 & 2.6712 \\
\hline 11 & 0.06 & 39 & 2.34 \\
\hline 12 & 0.0479 & 91 & 4.3589 \\
\hline 14 & 0.0449 & 89 & 3.9961 \\
\hline 15 & 0.0276 & 25 & 0.69 \\
\hline 16 & 0.043 & 86 & 3.698 \\
\hline 17 & 0.025 & 81 & 2.025 \\
\hline 18 & 0.0172 & 1 & 0.0172 \\
\hline 19 & 0.01 & 97 & 0.97 \\
\hline 20 & 0.017 & 100 & 1.7 \\
\hline 21 & 0.01 & 4 & 0.04 \\
\hline 23 & 0.0318 & 21 & 0.6678 \\
\hline 24 & 0.0083 & 10 & 0.0837 \\
\hline 25 & 0.0031 & 34 & 0.1066 \\
\hline 26 & -0.05 & 62 & -3.1 \\
\hline 28 & 0.0037 & 87 & 0.3266 \\
\hline 29 & -0.0488 & 55 & -2.6851 \\
\hline 30 & -0.0677 & 64 & -4.3380 \\
\hline
\end{tabular}
Function

From Table II, we can say that, bus number 12 have maximum fitness function so, select that bus and connect IPFC. The performance of capacity of IPFC and fitness function is given in Fig. 6.

IPFC was connected at bus 12 and voltage stability improvement of the system was analyzed. Similarly, the 
IPFC was connected at bus number 14 and the voltage stability improvement of the system was analyzed. Then, the analyzed voltage stability improvements are used for comparing the performance of the system without FACTS, with IPFC and with SVC. The voltage profiles obtained with FL-PSO based technique are better than the FL-genetic algorithm (GA) based technique. These two evolutionary approaches for optimal location of IPFC are compared when it is connected at buses 12 and 14 and are shown in Fig. $7 \& 8$ respectively. In Fig. 7, comparison of bus voltage magnitude of the system with and without IPFC at bus 12 using FL-GA and FL-PSO techniques. Similarly, in Fig. 8, comparison of bus voltage magnitude of the system with and without IPFC at bus 14 using FL-GA and FL-PSO techniques. The performance of IPFC at bus $12 \&$ 14 with proposed technique are compared with SVC and is illustrated in Fig. 9. The voltage magnitude comparison table is given in Table III.

From Fig. 7 and 8, we can say that the voltage profile of IEEE 30 bus system is improved by the proposed hybrid technique based on FL-PSO. Before connecting IPFC in the system, the voltage at bus 12 and 14 are 1.0572p.u. and 1.0414 p.u. and after connected IPFC at bus 12, voltage profile improvement is moved to 1.0553 p.u. and 1.0394p.u.. Similarly, after IPFC connected at bus 14, the voltage profile improvement moved to $1.0536 \mathrm{p} . u$. and 1.0369p.u.. When compared to SVC connected in the system, from Fig. 9, it says that the voltage profile is much deviated from FL-PSO method. And the power loss of the system is reduced from 10.809 MW to 6.9722 MW and $10.537 \mathrm{MW}$ due to IPFC at bus 12 and 14 respectively. The performance of power loss is illustrated in Fig. 10.

\section{CONCLUSIONS}

The proposed hybrid technique was implemented in MATLab working platform and tested with IEEE 30 bus system prototype. In the proposed hybrid technique, the optimal location of IPFC was determined by PSO algorithm and FL was used to determine the capacity of the IPFC. Optimal location of IPFC was determined based on fitness value due its most violated voltage. Maximum violated bus would be having maximum fitness value. Capacity of the connected IPFC was computed by FL based maximum and minimum voltage deviation ranges. So, FL determines the injected capacity of IPFC to be connected. After injected the active power, apply power flow analysis by NewtonRaphson method. Then, the real and reactive power of the system was analyzed; voltage stability and power loss of the system was also analyzed. Bus voltages stabilities were compared when no FACTS device, IPFC connected at bus 12 and 14 with FL-GA and FL-PSO methods. And IPFC at bus 12 and 14 using FL-PSO and SVC connected alone simulations were also compared. From these comparisons, simulation results showed that the proposed method has maintained better voltage stability. Hence, the proposed hybrid technique based on FL-PSO is better for maintaining power system voltage stability and reduced total power losses.

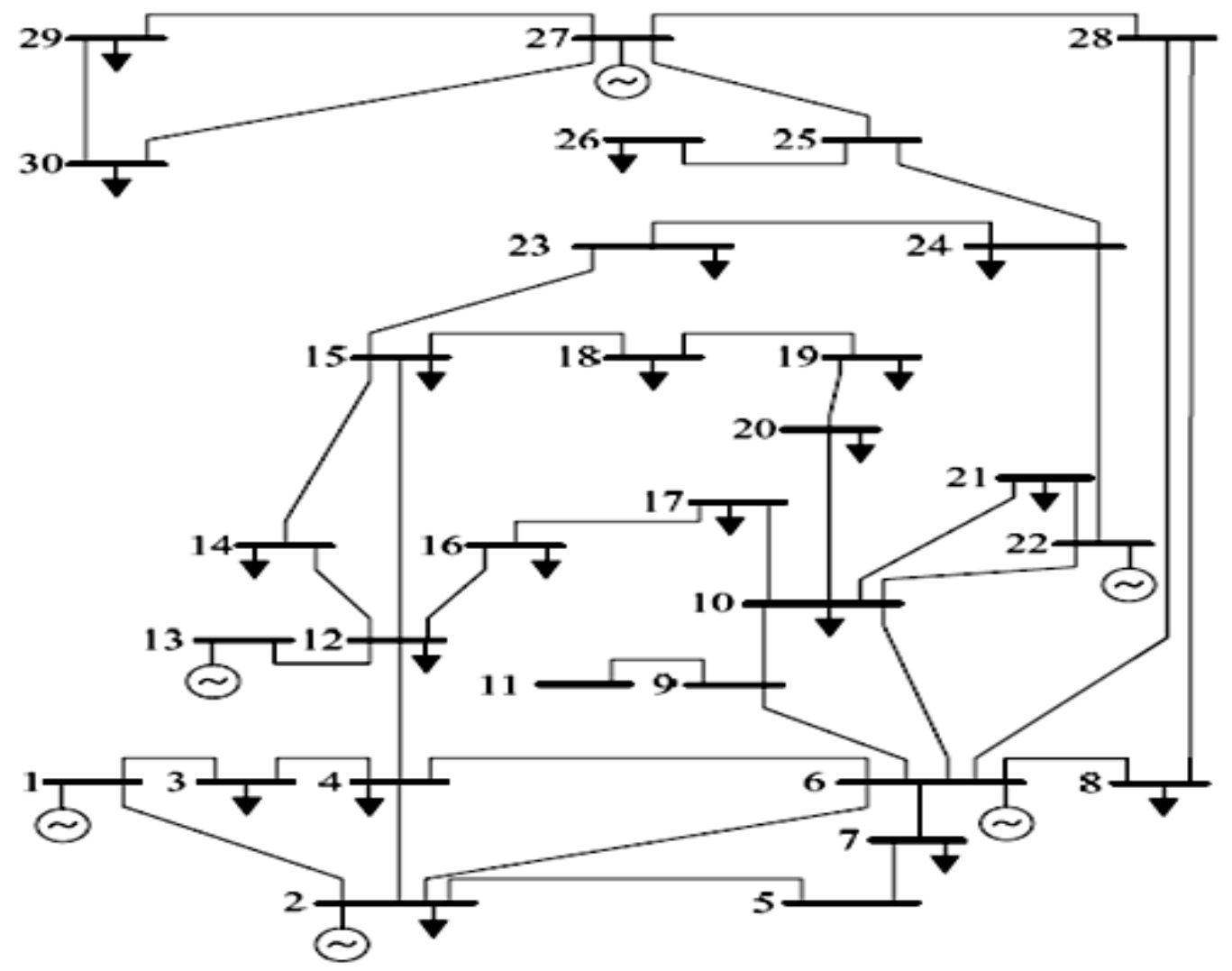

Fig. 5 Structure of IEEE 30 Bus Systems 


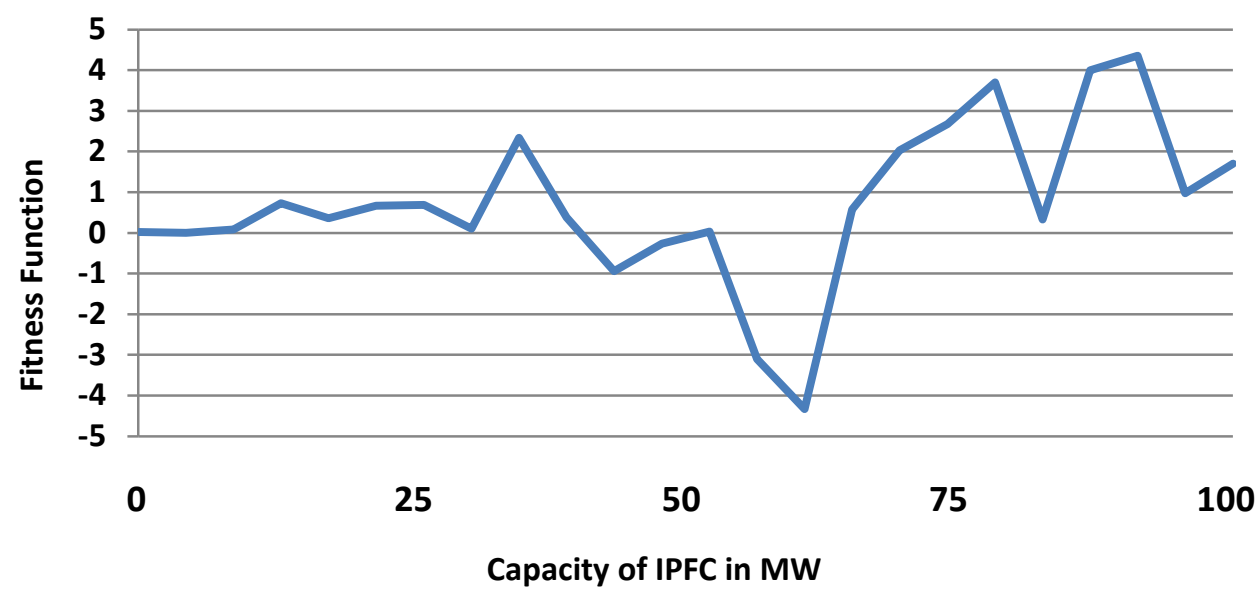

Fig. 6 Performance of Fitness Function vs. Capacity of IPFC

Table 3 The voltage magnitude comparison

\begin{tabular}{|c|c|c|c|c|c|c|}
\hline \multirow{2}{*}{$\begin{array}{r}\text { Bus } \\
\text { Number }\end{array}$} & \multicolumn{6}{|c|}{ Voltage Magnitude Improvements Before and After Connecting FACTS } \\
\hline & $\begin{array}{l}\text { Without } \\
\text { FACTS }\end{array}$ & $\begin{array}{c}\text { IPFC at } \\
\text { Bus } 12 \text { with } \\
\text { FL-GA }\end{array}$ & $\begin{array}{l}\text { IPFC at Bus } \\
12 \text { with } \\
\text { FL-PSO }\end{array}$ & $\begin{array}{r}\text { IPFC at } \\
\text { Bus } 14 \text { with } \\
\text { FL-GA }\end{array}$ & $\begin{array}{r}\text { IPFC at } \\
\text { Bus } 14 \text { with } \\
\text { FL-PSO }\end{array}$ & With SVC \\
\hline 1 & 1.06 & 1.06 & 1.06 & 1.06 & 1.06 & 1.06 \\
\hline 2 & 1.033 & 1.043 & 1.043 & 1.043 & 1.043 & 1.043 \\
\hline 3 & 1.0228 & 1.0246 & 1.0256 & 1.0246 & 1.0253 & 0.9977 \\
\hline 4 & 1.0136 & 1.0157 & 1.0169 & 1.0158 & 1.0165 & 0.9892 \\
\hline 5 & 1.0044 & 1.0095 & 1.0091 & 1.0095 & 1.0091 & 1.0100 \\
\hline 6 & 1.01 & 1.01 & 1.01 & 1.01 & 1.01 & 0.9947 \\
\hline 7 & 0.9999 & 1.002 & 1.0017 & 1.002 & 1.0018 & 0.9781 \\
\hline 8 & 1.0103 & 1.0103 & 1.0103 & 1.0103 & 1.0108 & 1.0100 \\
\hline 9 & 1.0458 & 1.0466 & 1.0438 & 1.0471 & 1.0397 & 1.0488 \\
\hline 10 & 1.0367 & 1.0378 & 1.0384 & 1.0384 & 1.0309 & 1.0502 \\
\hline 11 & 1.0771 & 1.0579 & 1.0675 & 1.0584 & 1.0636 & 1.0820 \\
\hline 12 & 1.0572 & 1.0573 & 1.0553 & 1.0572 & 1.0536 & 1.0537 \\
\hline 13 & 1.071 & 1.051 & 1.071 & 1.061 & 1.071 & 1.0710 \\
\hline 14 & 1.0414 & 1.0415 & 1.0394 & 1.0414 & 1.0369 & 1.0392 \\
\hline 15 & 1.0355 & 1.036 & 1.0352 & 1.0361 & 1.0322 & 1.0055 \\
\hline 16 & 1.0411 & 1.0418 & 1.0412 & 1.042 & 1.0369 & 1.0417 \\
\hline 17 & 1.0326 & 1.0336 & 1.034 & 1.0342 & 1.0274 & 1.0400 \\
\hline 18 & 1.0236 & 1.0244 & 1.0242 & 1.0247 & 1.0195 & 1.0250 \\
\hline 19 & 1.0198 & 1.0207 & 1.0208 & 1.0211 & 1.0151 & 1.0219 \\
\hline 20 & 1.0232 & 1.0242 & 1.0244 & 1.0247 & 1.0183 & 1.0278 \\
\hline 21 & 1.0228 & 1.0237 & 1.024 & 1.0241 & 1.0191 & 1.0505 \\
\hline 22 & 1.03 & 1.03 & 1.03 & 1.03 & 1.03 & 1.0392 \\
\hline 23 & 1.0229 & 1.0237 & 1.0239 & 1.0241 & 1.02 & 1.0465 \\
\hline 24 & 1.0158 & 1.016 & 1.0159 & 1.0161 & 1.023 & 1.0240 \\
\hline 25 & 1.0069 & 1.007 & 1.0068 & 1.007 & 1.0496 & 1.0084 \\
\hline 26 & 0.989 & 0.9891 & 0.98896 & 0.9891 & 1.0325 & 0.9832 \\
\hline 27 & 1.01 & 1.01 & 1.01 & 1.01 & 1.01 & 1.0109 \\
\hline 28 & 1.0094 & 1.0095 & 1.0098 & 1.0096 & 1.0127 & 0.9963 \\
\hline 29 & 0.9899 & 0.9899 & 0.98987 & 0.999 & 0.98987 & 0.9821 \\
\hline 30 & 0.9782 & 0.9982 & 0.97823 & 0.9982 & 0.97823 & 0.9655 \\
\hline
\end{tabular}




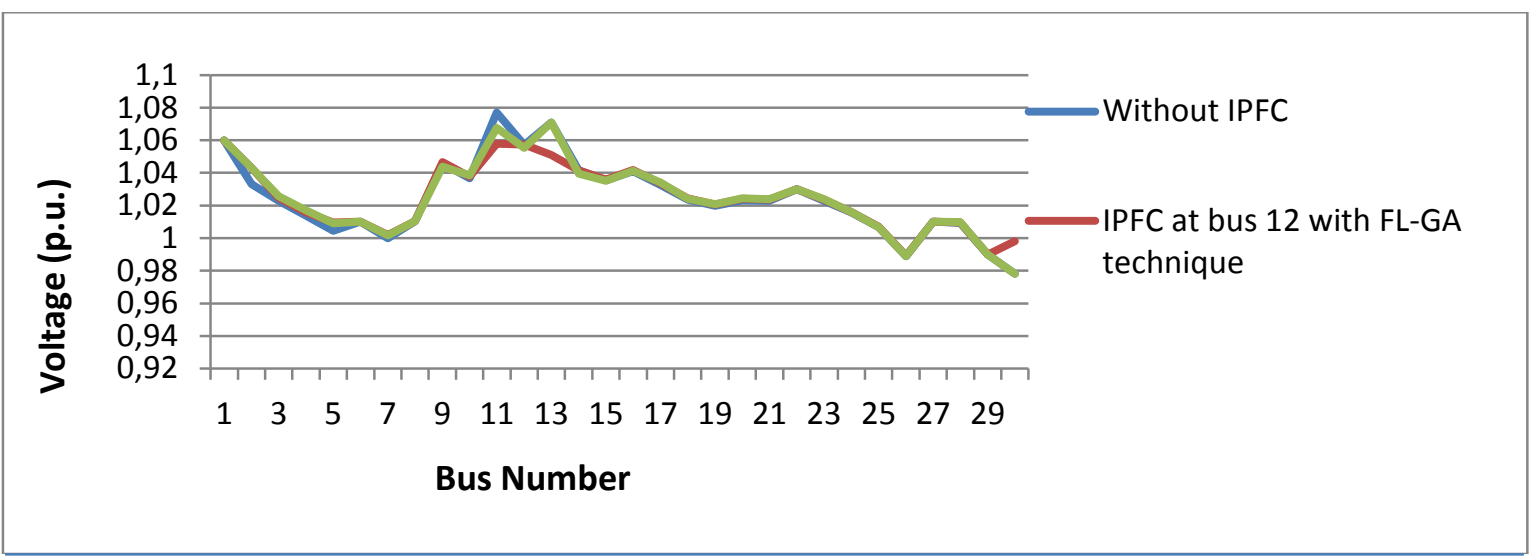

Fig. 7 Comparison Performance of Bus voltage when IPFC at 12

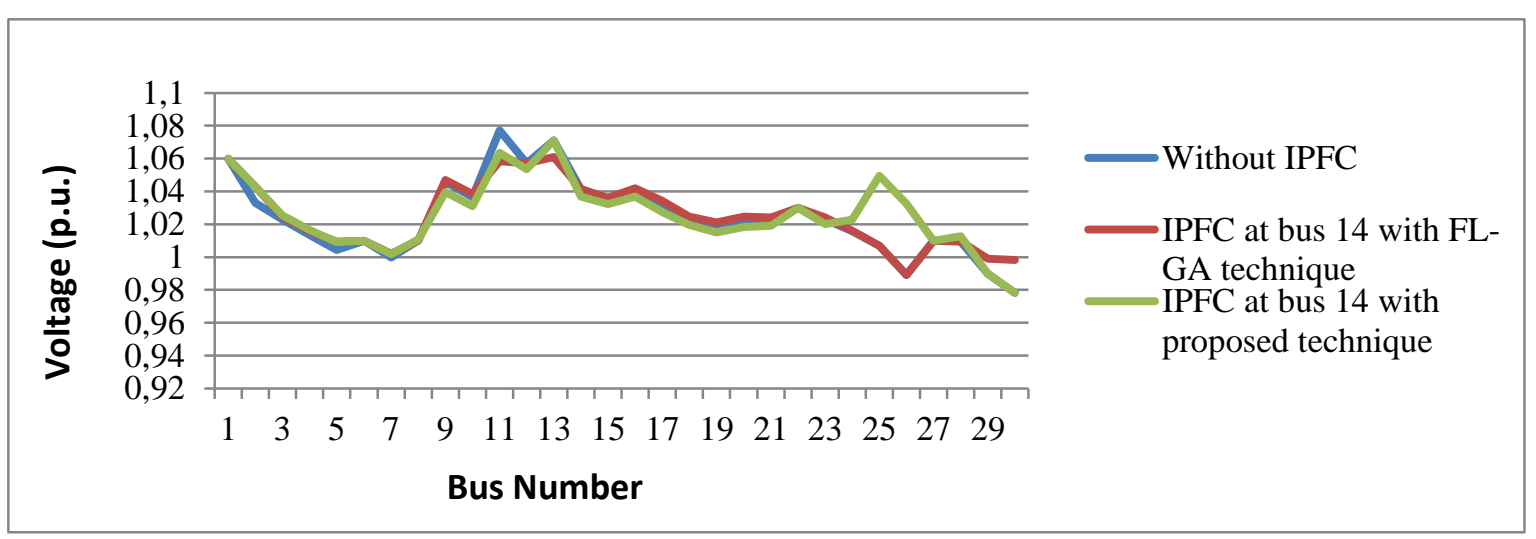

Fig. 8 Comparison Performance of Bus voltage when IPFC at 14

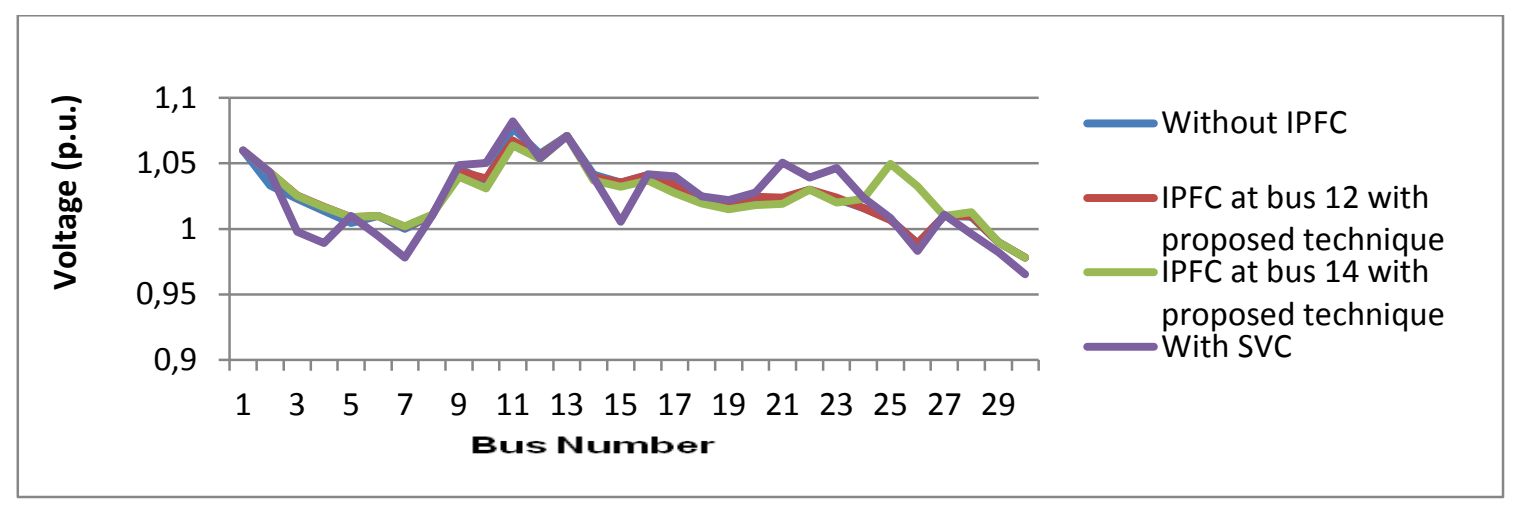

Fig. 9 Comparison Performance of Voltage Magnitude while SVC alone and IPFC

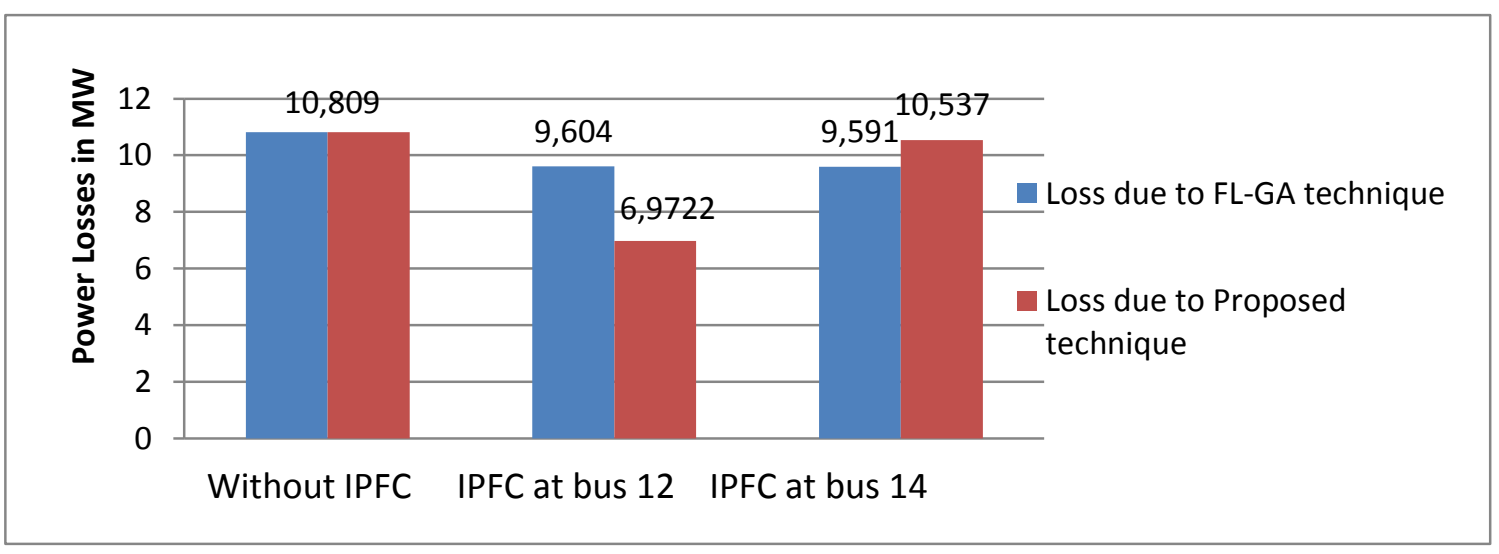

Fig. 10 Power Loss Comparison of FL-GA and Proposed method 


\section{REFERENCES}

[1] BINDESHWAR, S. - SHARMA, N. K. - TIWARI, A. N.: Prevention of Voltage Instability by Using FACTS Controllers in Power Systems: A Literature Survey, International Journal of Engineering Science and Technology, Vol.2, No.5, pp.980-992, 2010.

[2] EASWARAMOORTHY,N.K.-DHANASEKARAN, R. - SUNDARARAJ, N. K.: Simulation of Optimal Power Flow incorporating with Fuzzy Logic Control and various FACTS Devices, International Journal of Scientific and Research Publications, Vol.2, No.5, pp.1-5, 2012.

[3] JULLURI NAMRATHA, M. - AMARNATH, J. VEMURI POORNACHANDRA, R.: Optimization of Loss Minimization Using FACTS in Deregulated Power Systems, International Institute for Science, Technology and Education: Innovative Systems Design and Engineering, Vol.3, No.3, pp.47-57, 2012.

[4] MONDAL, D. - CHAKRABARTI, A. SENGUPTA, A.: Small Signal Stability Assessment Employing PSO Based TCSC Controller with Comparison to GA Based Design, World Academy of Science, Engineering and Technology Vol.80, pp.1594-1601, 2011.

[5] NANDA KUMAR, E. - DHANASEKARAN, R.: Solution of Optimal Power Flow Problem Incorporating Various FACTS Devices, International Journal of Computer Applications, Vol.55, No.4, pp.38-44, 2012.

[6] VIJAYAKUMAR, K. - KUMUDINIDEVI, R. P.: A New Method for Optimal Location of FACTS Controllers using Genetic Algorithm, Journal of Theoretical and Applied Information Technology, Vol.3, No.4, pp.1-6, 2005.

[7] MOHAMAD IDRIS, R. - KHAIRUDDIN, A. MUSTAFA, M. W.: Optimal Allocation of FACTS Devices in Deregulated Electricity Market Using Bees Algorithm, WSEAS Transactions on Power Systems, Vol.5, No.2, pp.108-119, 2010.

[8] CAI, L. J. - ERLICH, I. - STAMTSIS, G.: Optimal choice and allocation of FACTS devices in deregulated electricity market using genetic algorithms, Power Systems Conference and Exposition, Vol.1, pp.201-207, 2004.

[9] ALOK KUMAR, M. - AMAR KUMAR, B.: Power System Stability Improvement Using FACTS Devices, International Journal of Modern Engineering Research, Vol.1, No.2, pp.666-672.

[10] NARESH BABU, A. V. - SIVANAGARAJU, S.: A New Approach for Optimal Power Flow Solution Based on Two Step Initialization with Multi-Line FACTS Device, International Journal on Electrical Engineering and Informatics, Vol.4, No.1, pp.173$185,2012$.

[11] KARTHIK, B. - CHANDRASEKAR, S.: Modeling of IPFC for Power Flow control in 3-Phase lineFurther Aspects and its Limitations, International Journal of Computer and Electrical Engineering, Vol.4, No.2, pp.227-230, 2012.

[12] RAJSHEKAR, S. - VIJAY KUMAR, K.: Role of Interline Power Flow Controller for Voltage Quality, International Journal of Advances in Electrical and Electronics Engineering, Vol.1, No.2, pp.271-277.

[13] GOMATHI, V. - VENKATESHKUMAN, C. RAMACHANDRAN, V.: State Estimation of Power System with Interline Power Flow Controller, International Journal on Electrical and Power Engineering, Vol.1, No.2, pp.56-60, 2010.

[14] NARESH BABU, A. V. - SIVANAGARAJU, S. PADMANABHARAJU, CH. - RAMANA, T.: MultiLine Power Flow Control using Interline Power Flow Controller (IPFC) in Power Transmission Systems, International Journal of Electrical and Electronics Engineering, pp.492-496, 2010.

[15] NARESH BABU, A. V. - SIVANAGARAJU, S. PADMANABHARAJU, CH. - RAMANA, T.: Power Flow Analysis of a Power System in the Presence of Interline Power Flow Controller (IPFC), ARPN Journal of Engineering and Applied Sciences, Vol.5, No.10, pp.1-4, 2010.

[16] PRECHANON, K.: Application of Interline Power Flow Controller to Increase Transient Stability of Power System, Journal of Computer Science, Vol.6, No.12, pp.1490-1493, 2010.

[17] AKHILES, A. N. - CHINMOY KUMAR, P. AJAYA KUMAR, M.: Interline Power Flow Controller: Review Paper, International Electrical Engineering Journal, Vol.2, No.3, pp.550-554, 2011.

[18] JENICA ILEANA, C. - STOENESCU, E.: Fuzzy logic controller as a power system stabilizer, International Journal of Circuits, Systems and Signal Processing, Vol.1, No.3, pp.266-273, 2007.

[19] AL-TURKI, Y. A. - ATTIA, A. F. - SOLIMAN, H. F.: Optimization of Fuzzy Logic Controller for Supervisory Power System Stabilizers, Acta Polytechnica, Vol.52, No.2, pp.7-16, 2012.

[20] UMARANI, R. - SELVI, V.: Particle Swarm Optimization-Evolution, Overview and Applications, International Journal of Engineering Science and Technology, Vol.2, No.7, pp.2802-2806, 2010.

[21] JAMES BLONDIN: Particle Swarm Optimization: A Tutorial, $\quad$ September $4, \quad 2009$. http://www.cs.armstrong.edu/saad/csci8100/pso_tuto rial.pdf.

[22] KENNEDY, J. - EBERHART, R.: Particle swarm optimization. In Proceedings of the IEEE International Conference on Neural Networks, volume IV, pages 1942-1948, Piscataway, NJ, 1995. IEEE Press.

Received Novemer 5, 2014, accepted March 9, 2015 


\section{BIOGRAPHIES}

Sri. B.V.Rami Reddy had completed his B.Tech and M.Tech in 1999 and 2005 with first class in the department of Electrical and Electronics Engineering from J.N.T.University Hyderabad. Now he is pursuing his $\mathrm{PhD}$ in J.N.T. University, Ananthapur. He is working as a Associate Professor in the Department of Electrical and Electronics Engineering. His scientific research is focusing on Power Systems and Distribution Systems.

Dr. P.Sujatha has completed her B.Tech and M.Tech in 1993 and 2003 in the department of Electrical and Electronics Engineering from J.N.T.University Hyderabad and her Doctorate degree from J.N.T. University,
Ananthapur in 2011. Now she is working as a Professor and Head of the Department of Electrical and Electronics Engineering in J.N.T.University college of Engineering, Ananthapuramu. Her scientific research is focusing on Power Systems and Energy Management.

Dr. Y.V.Siva Reddy had completed his B.Tech and M.Tech in 1995 and 2000 in the department of Electrical and Electronics Engineering from J.N.T.University Hyderabad and obtained doctoral degree from J.N.T. University, Ananthapur in 2010. He is working as a Professor in the Department of Electrical and Electronics Engineering in G.P.R Engineering College, Kurnool. His areas of research are Power Systems and Industrial Drives. 